\title{
Effect of spectrally varying albedo of vegetation surfaces on shortwave radiation fluxes and aerosol direct radiative forcing
}

\author{
L. Zhu ${ }^{1}$, J. V. Martins ${ }^{1}$, and H. Yu ${ }^{2,3}$ \\ ${ }^{1}$ University of Maryland, Baltimore County, Department of Physics and Joint Center for Earth Systems Technology, \\ 1000 Hilltop Circle, Baltimore, MD, 21250, USA \\ ${ }^{2}$ Earth System Science Interdisciplinary Center (ESSIC) University of Maryland, College Park, MD, 20740, USA \\ ${ }^{3}$ Climate and Radiation Laboratory, NASA Goddard Space Flight Center, Greenbelt, MD, 20771, USA
}

Correspondence to: L. Zhu (zhuli1 @umbc.edu), J. V. Martins (martins@umbc.edu) and H. Yu (hongbin.yu@ nasa.gov)

Received: 24 April 2012 - Published in Atmos. Meas. Tech. Discuss.: 7 June 2012

Revised: 1 November 2012 - Accepted: 2 November 2012 - Published: 12 December 2012

\begin{abstract}
This study develops an algorithm for representing detailed spectral features of vegetation albedo based on Moderate Resolution Imaging Spectrometer (MODIS) observations at 7 discrete channels, referred to as the MODIS Enhanced Vegetation Albedo (MEVA) algorithm. The MEVA algorithm empirically fills spectral gaps around the vegetation red edge near $0.7 \mu \mathrm{m}$ and vegetation water absorption features at 1.48 and $1.92 \mu \mathrm{m}$ which cannot be adequately captured by the MODIS 7 channels. We then assess the effects of applying MEVA in comparison to four other traditional approaches to calculate solar fluxes and aerosol direct radiative forcing (DRF) at the top of atmosphere (TOA) based on the MODIS discrete reflectance bands. By comparing the DRF results obtained through the MEVA method with the results obtained through the other four traditional approaches, we show that filling the spectral gap of the MODIS measurements around $0.7 \mu \mathrm{m}$ based on the general spectral behavior of healthy green vegetation leads to significant improvement in the instantaneous aerosol DRF at TOA (up to $3.02 \mathrm{~W} \mathrm{~m}^{-2}$ difference or $48 \%$ fraction of the aerosol DRF, $-6.28 \mathrm{~W} \mathrm{~m}^{-2}$, calculated for high spectral resolution surface reflectance from 0.3 to $2.5 \mu \mathrm{m}$ for deciduous vegetation surface). The corrections of the spectral gaps in the vegetation spectrum in the near infrared, again missed by the MODIS reflectances, also contributes to improving TOA DRF calculations but to a much lower extent (less than $0.27 \mathrm{~W} \mathrm{~m}^{-2}$, or about $4 \%$ of the instantaneous DRF).
\end{abstract}

Compared to traditional approaches, MEVA also improves the accuracy of the outgoing solar flux between 0.3 to $2.5 \mu \mathrm{m}$ at TOA by over $60 \mathrm{~W} \mathrm{~m}^{-2}$ (for aspen 3 surface) and aerosol
DRF by over $10 \mathrm{~W} \mathrm{~m}^{-2}$ (for dry grass). Specifically, for Amazon vegetation types, MEVA can improve the accuracy of daily averaged aerosol radiative forcing in the spectral range of 0.3 to $2.5 \mu \mathrm{m}$ at equator at the equinox by $3.7 \mathrm{~W} \mathrm{~m}^{-2}$. These improvements indicate that MEVA can contribute to regional climate studies over vegetated areas and can help to improve remote sensing-based studies of climate processes and climate change.

\section{Introduction}

Vegetation-covered land surface and the climate are linked together through complex ecological, hydrological, and biogeochemical processes (Dickinson, 1983, 1995; Dirmeyer and Shukla, 1994; Lyapustin, 1999; Betts, 2000; Lucht et al., 2002). Among these processes, the surface directly reflects the solar radiation and affects the Earth's energy balance, and hence the climate (Cess, 1978; Lofgren, 1995). The knowledge of the surface albedo properties affects earthatmosphere system related calculations and retrievals such as the direct aerosol forcing calculation (Yu et al., 2006; McComiskey et al., 2008) and cloud properties retrieval (Popp et al., 2011). The vegetation surface albedo and its spectral variation are affected by leaf structure, water content, pigment, chlorophyll, etc. (Collins, 1978; Kim et al., 1994; Asner et al., 2000; Ceccato et al., 2001). The black sky albedo calculated from the Moderate Resolution Imaging Spectroradiometer (MODIS) data shown in Fig. 1 indicates that vegetation albedo has large spatial and spectral variations.

Published by Copernicus Publications on behalf of the European Geosciences Union. 

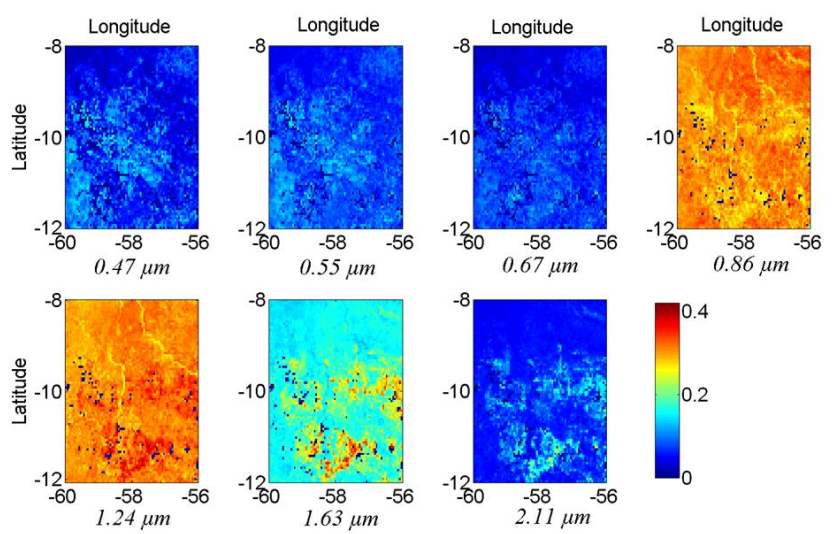

Fig. 1. Black sky albedo maps at MODIS bands 1-7 calculated from the MODIS file MCD43C1.A2006241.005.2008109074010.hdf with SZA equaling 32 degrees. The studied area is over Amazonian in Latitude $=[-12$ to -8$]$ and Longitude $=[-60$ to -56$]$ on Julian day 241 in 2006.

Adequate representation of these variations is important for estimating radiative flux and aerosol radiative forcing.

Much work has been done to capture vegetation surface reflectance and albedo. Directly, surface albedo can be obtained from field measurements (Gilgen et al., 1995; Sellers et al., 1992; Hall and Sellers, 1995). Leaf samples have also been collected and their reflectance has been determined by spectrophotometers in the laboratory (Hosgood et al., 1994; Clark et al., 2007). Additionally, remote sensing techniques have been widely used to determine surface albedo, for instance the Airborne Visible/Infrared Imaging Spectrometer (AVIRIS) (Staenz et al., 1996), and many satellite instruments including, but not limited to: Global Ozone Monitoring Experiment (GOME) (Koelemeijer et al., 2003), MEdium Resolution Imaging Spectrometer (MERIS) (Muller, 2006), Polarization and Directionality of the Earth's Reflectances (POLDER) (Leroy et al., 1997), Multiangle Imaging Spectroradiometer (MISR) (Diner, 2008), Advanced Very High Resolution Radiometer (AVHRR) (Saunders, 1990), Visible Infrared Imager Radiometer Suite (VIIRS) (Sei, 2011), and Moderate Resolution Imaging Spectroradiometer (MODIS) (Liang et al., 1999; Lucht et al., 2000; Schaaf et al., 2002; Moody et al., 2005).

The MODIS sensor on board the NASA polar satellites TERRA (1999-present) and AQUA (2000-present) measures the reflected solar radiation at the top of the atmosphere (TOA), which can be used to retrieve surface properties (Vermote et al., 1997). The MODIS land science team has used the MODIS measurements to develop a series of surface albedo data products, including MCD43C, among others. In detail, MCD43C provides three spectrally dependent parameters $f_{\text {iso }}, f_{\text {vol }}, f_{\text {geo }}$ for calculating black sky albedo and white sky albedo when combined with a BRDF model. These parameters are available at MODIS bands 1-7 (nominally centered at $0.47,0.55,0.67,0.86,1.24,1.63$, and $2.11 \mu \mathrm{m}$ ), and in the spectral ranges of visible $(0.3$ to $0.7 \mu \mathrm{m})$, near infrared $(0.7$ to $5 \mu \mathrm{m})$, and total broadband $(0.3$ to $5 \mu \mathrm{m})$.

Satellite remote sensing techniques have the advantages of having larger spatial and longer temporal coverage than in situ measurements. However, most satellite sensors can only measure reflectance at certain narrow bands and have the drawback of inadequately characterizing spectral variations as the example shown in Fig. 2. Clearly MODIS spectral measurements don't well capture the rapid increase of reflectance from 0.67 to $0.86 \mu \mathrm{m}$ and the dips at 1.48 and $1.92 \mu \mathrm{m}$. For flux and aerosol forcing calculations, broadband albedo is generally used and narrow band albedo is usually ignored (Myhre et al., 2005; Zhou et al., 2005; Patadi et al., 2009). The limited spectral reflectance information and the simplified broad band albedos can be error prone in radiative forcing calculations (Wang et al., 2011).

This work presents a new algorithm - the MODIS enhanced vegetation albedo (MEVA) - to provide an integrated vegetation reflectance spectrum, with the advantage of global and temporal coverage over the lifetime of MODIS. Given reflectance at MODIS bands $1-7$, this project demonstrates that the vegetation reflectance spectrum determined by the MEVA algorithm improves the accuracy of the TOA flux and aerosol forcing calculations.

\section{Methodology}

\subsection{Traditional approaches}

Several methods have been traditionally used to integrate the surface albedo over the whole solar spectrum based on the MODIS bands 1-7. These methods are illustrated in Fig. 3, based on the reflectance spectrum of miconia guianensis adapted from Arai et al. (2010) and can be described as: (a) the narrowband reflectance is converted to reflectance in total shortwave broadband (from 0.3 to $2.5 \mu \mathrm{m}$ ) (Liang et al., 1999); (b) narrowband reflectance at MODIS bands $1-7$ is converted to reflectance in two broad bands: broadband "visible" (from 0.3 to $0.7 \mu \mathrm{m}$ ) and "near infrared" (from 0.7 to $2.5 \mu \mathrm{m}$ ) according to Liang et al. (1999); (c) the wavelength between two adjacent MODIS channels are averaged (which leads to $0.51,0.61,0.77,1.10,1.44$, and $1.87 \mu \mathrm{m}$ ) and seven reflectance values from MODIS centered in the native wavelengths are assigned to the following bands: from 0.3 to 0.51 $\mu \mathrm{m}$, from 0.51 to $0.61 \mu \mathrm{m}$, and so on (denoted "average band MODIS" in following discussions); (d) the reflectance at MODIS bands 1-7 is linearly interpolated. The approach in methods (a) and (b) is performed through polynomial regressions to convert albedos at MODIS narrow bands to broadband albedos at visible, near infrared, and total shortwave as described in Liang et al. (1999).

This research will show that all of these traditional techniques produce significant errors in estimating TOA radiative fluxes and aerosol forcing. The new methodology proposed 


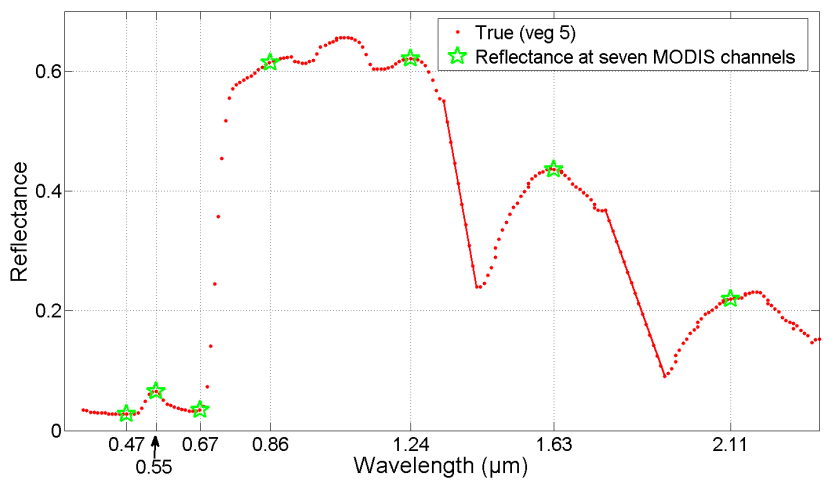

Fig. 2. The x-axis represents the wavelength from 0.3 to $2.35 \mu \mathrm{m}$ labeled by seven MODIS channels; the dotted red curve is the spectral reflectance for vegetation 5 (miconia guianensis) adapted from Arai et al. (2010); the green stars represent the corresponding reflectance at MODIS bands 1-7. In this figure, the spectral reflectance results between 1.35 to $1.45 \mu \mathrm{m}$ and 1.85 to $1.95 \mu \mathrm{m}$ were linearly interpolated based on Arai et al. (2010) data. These solid red lines are shown as dots in Figs. 3, 5, 6, and 9.

here based on MODIS bands 1-7 (MEVA-MODIS enhanced vegetation albedo) will minimize these errors. TOA solar fluxes and aerosol direct radiative forcing will be calculated for all these methods (traditional and proposed) and will be compared with the results calculated from the high resolution spectral libraries.

Using the reflectance spectrum of vegetation miconia guianensis adopted from Arai et al. (2010) as an example, Fig. 3 illustrates results from the four traditional approaches described above. As shown by the solid blue line in Fig. 3d, it is possible to linearly connect reflectance at MODIS bands 1-7 in order to interpolate the reflectance data. However, in this method, there are three distinct features missing from the actual spectrum, which can be seen in the shadowed areas in Fig. 4b.

The first missing feature is associated with the vegetation red edge around $0.7 \mu \mathrm{m}$, which is the division between the low reflectance in the visible and high reflectance in the near infrared. The red edge in the vegetation surface reflectance spectra have been used to study chlorophyll, water content, pigment content properties, and more (Horler et al., 1983; Guyot et al., 1992; Gitelson et al., 1996; Sims and Gamon, 2002; Stimson et al., 2005). As shown in Fig. 4a, solar radiation arriving at the surface is relatively strong around $0.7 \mu \mathrm{m}$, which intensifies the errors in flux and aerosol forcing calculations associated with the missing feature of the red edge. The other two important missing features in the interpolated spectrum are around 1.44 and $1.92 \mu \mathrm{m}$ due to radiation absorption by vegetation water. These two missing features are expected to lead to smaller errors, due to the weaker solar radiation arriving at the surface resulting from the strong atmospheric water vapor absorption in these two spectral ranges as shown in Fig. 4a. These errors are discussed in more de-
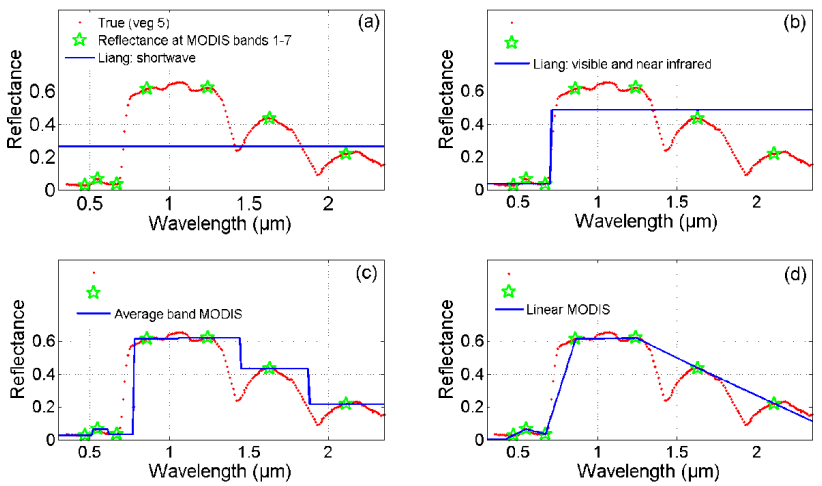

Fig. 3. Traditional approaches to estimate the continuous reflectance spectra based on MODIS bands 1-7: Liang short wave, Liang visible and near infrared, average band MODIS, and linear MODIS. In each subplot, the $\mathrm{x}$-axis represents the wavelength from 0.3 to $2.35 \mu \mathrm{m}$; the dotted red curve is the spectral reflectance for miconia guianensis as shown in Fig. 2; the green stars represent the corresponding reflectance at MODIS bands 1-7; the solid blue lines represent each traditional approach.

tail in the following section through flux and aerosol forcing calculation in different spectral ranges.

\subsection{MODIS enhanced vegetation albedo (MEVA)}

We now describe a new empirical method which will show how the seven MODIS narrowband albedos can be extended in a continuous reflectance spectrum to minimize errors in the calculation of fluxes at the TOA and lead to more accurate aerosol radiative forcing calculations.

The MODIS enhanced vegetation albedo (MEVA) algorithm is proposed here to minimize the errors in flux and aerosol forcing calculations associated with these missing features. In addition to MODIS 7 channels, MEVA includes 7 auxiliary channels $(0.69,0.72$, a variable channel at the top of the red edge, 1.44, 1.84, 1.92, and $3 \mu \mathrm{m}$ ). Four of these auxiliary channels are shown in Fig. 5: the reflectance at $0.69 \mu \mathrm{m}$ is obtained by linearly extrapolating the reflectance at 0.55 and $0.67 \mu \mathrm{m}$; the reflectance at $0.72 \mu \mathrm{m}$ is the average between $0.69 \mu \mathrm{m}$ and $0.86 \mu \mathrm{m}$; the reflectance at $1.44 \mu \mathrm{m}$ is $40 \%$ of the reflectance at $1.24 \mu \mathrm{m}$; the reflectance at $1.92 \mu \mathrm{m}$ is $20 \%$ of the reflectance value at $1.63 \mu \mathrm{m}$. The remaining three auxiliary channels are a variable channel at the top of the red edge, and at 1.84 and $3 \mu \mathrm{m}$ as shown in Fig. 6 . The variable channel at the top of the red edge is defined as the crossing point between the linearly extrapolated line connecting 0.69 to $0.72 \mu \mathrm{m}$ and the linearly extrapolated line connecting 1.24 and $0.86 \mu \mathrm{m}$; the reflectance at $1.84 \mu \mathrm{m}$ is determined by linearly interpolating the reflectance at 1.63 and $2.11 \mu \mathrm{m}$; the reflectance at $3 \mu \mathrm{m}$ is set to zero. Finally, the reflectance between 0.3 and $0.4 \mu \mathrm{m}$ were set constant to the reflectance at $0.47 \mu \mathrm{m}$. The auxiliary channels and the values of ratios were determined here by the general behavior 

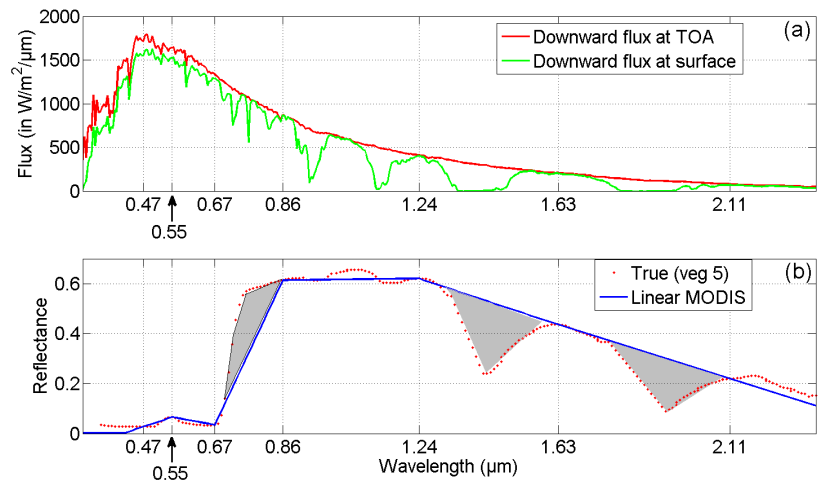

Fig. 4. (a) Downward fluxes at the TOA and surface. The $x$-axis is the wavelength (from 0.3 to $2.5 \mu \mathrm{m}$ ) labeled with MODIS bands 17; the red curve represents the incoming solar radiation at the top of the atmosphere (TOA); the green curve represents the downward radiation reaching the surface. The simulation was done with the following inputs: no boundary layer aerosols, $\mathrm{SZA}=30$ degrees, tropical atmospheric profile, and surface albedo being as the red curve in Fig. 2. (b) The three missing features by linearly connecting the reflectance at MODIS bands 1-7. The x-axis is the wavelength from 0.3 to $2.5 \mu \mathrm{m}$ labeled with MODIS bands $1-7$; the dotted red curve represents the reflectance as shown in Fig. 2; the solid blue line represents the linearly connected reflectance at MODIS bands 1-7; the shaded areas represent three distinct missing features: missing vegetation red edge feature at around $0.7 \mu \mathrm{m}$, and the missing water absorption features at around 1.44 and $1.92 \mu \mathrm{m}$.

of vegetation spectra including the vegetation red edge associated with chlorophyll absorption at $0.7 \mu \mathrm{m}$ and vegetation water absorption features at about 1.5 and $1.9 \mu \mathrm{m}$ (Hoffer, 1987). The final result is a reflectance spectrum based on the MODIS bands 1-7 that better resembles the most important features of a typical vegetation spectral reflectance. With $m i$ conia guianensis (named "vegetation 5" in the discussion) as an example, the MEVA spectrum is displayed as the solid blue line in Fig. 6.

\section{Evaluation of the methodology}

In order to evaluate the relative merits of the MEVA methodology versus traditional approaches to interpolate the MODIS bands 1-7, several high-resolution vegetation spectra from the literature were used as input to the Santa Barbara DISORT Atmospheric Radiative Transfer (SBDART) program (Ricchiazzi et al., 1998) to calculate examples of the outgoing flux at TOA and the direct aerosol forcing. Here the direct radiative forcing is defined as the difference of net (incoming minus outgoing) solar flux at TOA under clear sky with and without aerosols. A positive direct aerosol forcing value indicates that aerosols warm the earth-atmosphere system, and a negative value shows that aerosols cool the earthatmosphere system.

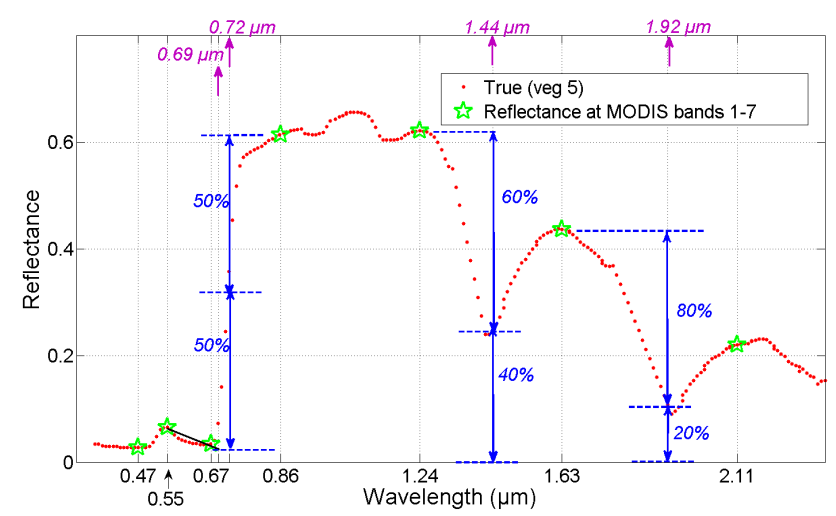

Fig. 5. This figure illustrates four auxiliary channels and the ratios used to determine the MODIS enhanced surface albedo (MEVA), where the $\mathrm{x}$-axis represents wavelength (from 0.3 to $2.35 \mu \mathrm{m}$ ) labeled with MODIS bands 1-7 on the bottom and four auxiliary channels $(0.69,0.72,1.44$, and $1.92 \mu \mathrm{m})$ at the top. Dotted red curve ("true") represents the reflectance spectrum as shown in Fig. 2; the green stars present the corresponding reflectance at MODIS bands 1-7. The reflectance at the four auxiliary channels are determined as: at $0.69 \mu \mathrm{m}$, the reflectance is obtained by linearly extrapolating the reflectance at 0.55 and $0.67 \mu \mathrm{m}$; at $0.72 \mu \mathrm{m}$, the reflectance is the average of the reflectance at 0.69 and $0.86 \mu \mathrm{m}$; at $1.44 \mu \mathrm{m}$, the reflectance is $40 \%$ of the reflectance at $1.24 \mu \mathrm{m}$; at $1.92 \mu \mathrm{m}$, the reflectance is $20 \%$ of the reflectance at $1.63 \mu \mathrm{m}$.

The SBDART is a radiative transfer model based on the discrete ordinate method which includes aerosols, gases, and surface properties (Ricchiazzi et al., 1998) and can run with different atmospheric input settings and customized spectral surface albedo. For this study, the main input parameters are the spectral surface albedo in a spectral range of $0.3 \mu \mathrm{m}$ to $2.5 \mu \mathrm{m}$ with a $0.01 \mu \mathrm{m}$ resolution; the spectral aerosol singlescattering albedo (SSA), aerosol optical depth (AOD), and phase function in a spectral range of $0.3 \mu \mathrm{m}$ to $2.5 \mu \mathrm{m}$ with a resolution of $0.1 \mu \mathrm{m}$ to $0.2 \mu \mathrm{m}$; and the standard tropical atmospheric profile. The phase function was represented by 128 terms of Legendre moments calculated with Mie theory based on the Amazonian aerosol model presented by Dubovik et al. (2002). The outputs are the flux at TOA in $\mathrm{W} \mathrm{m}^{-2} \mu \mathrm{m}^{-1}$ from 0.3 to $2.5 \mu \mathrm{m}$ with a default resolution of $0.005 \mu \mathrm{m}$.

During the simulation, the surface is assumed to be Lambertian and albedo is equal to reflectance. This approximation makes significant errors for directional radiance calculations but not so for the total TOA flux and aerosol forcing calculations. In addition, the MODIS surface albedo product already considers the surface BRDF effect. Thus we consider this approximation to be acceptable for this study. We also assume that the surface albedo doesn't depend on solar zenith angle. This assumption doesn't introduce significant errors to the calculation of daily averaged aerosol radiative forcing (Yu et al., 2004). 


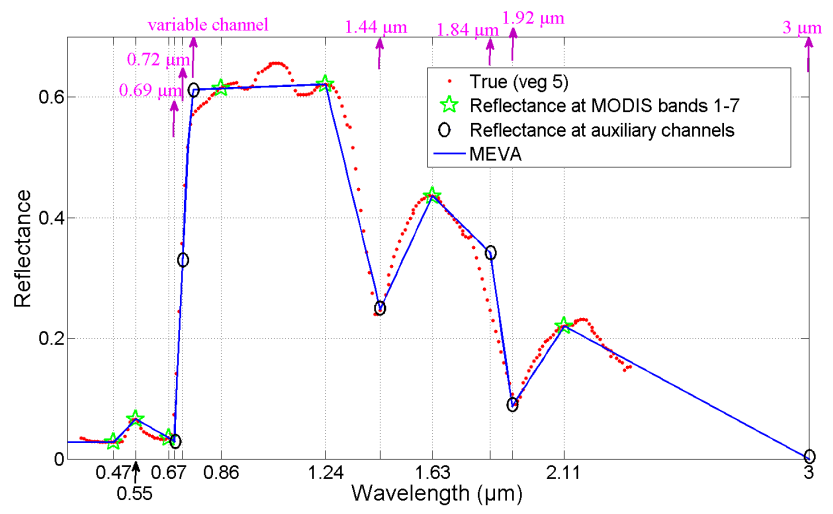

Fig. 6. Processes used to develop MEVA. The $x$-axis is wavelength (from 0.3 to $3 \mu \mathrm{m}$ ) labeled with MODIS bands $1-7$ on the bottom and the auxiliary channels $(0.69,0.72$, the variable channel ending the red edge, $1.44,1.84,1.92$, and $3 \mu \mathrm{m}$ ) at the top. Four of these auxiliary channels were shown in Fig. 5. For the other three auxiliary channels, the variable channel ending the red edge is the crossing point between the linearly extrapolated line from 0.69 to $0.72 \mu \mathrm{m}$ and the linearly extrapolated line from 1.24 to $0.86 \mu \mathrm{m}$; the auxiliary channel at 1.84 and $3 \mu \mathrm{m}$ are determined by averaging the experimental results of several types of vegetation. The dotted red curve ("true") represents reflectance spectra as shown in Fig. 2; the green stars present the corresponding reflectance at MODIS bands 1-7; the ovals represent the determined reflectance at auxiliary channels; the solid blue line represents MEVA. The detailed procedures for MEVA are explained in Sect. 2.2.

One possible scenario for biomass burning aerosols over the Amazon region is studied here using the following input parameters: AOD (at $0.55 \mu \mathrm{m})=0.32$ and 0.64 , SSA (at $0.55 \mu \mathrm{m})=0.89$, and solar zenith angle $(\mathrm{SZA})=30$ degrees . Cases with different AODs, SSAs, and SZAs were also studied, and will be discussed in the next section. The vegetation reflectance spectra used in this study (denoted "true" in following discussions) were taken from the Johns Hopkins University (JHU) spectral library, the United States Geological Survey (USGS) Digital Spectral Library (Clark et al., 2007), and from the spectral signatures of leaves from Amazonian trees presented by Aria et al. (2010). The MODIS data has $500 \mathrm{~m}$ spatial resolution and might contain mixtures of different land and vegetation types. This is a limitation of this study which uses the laboratory measurement of the leaf spectral reflectance as the land surface albedo in radiative transfer simulations. Since one main application of MEVA in this study is the calculation of biomass burning aerosol forcing and TOA flux calculation over the Amazon where green vegetation dominates over the whole year, this assumption is appropriate.
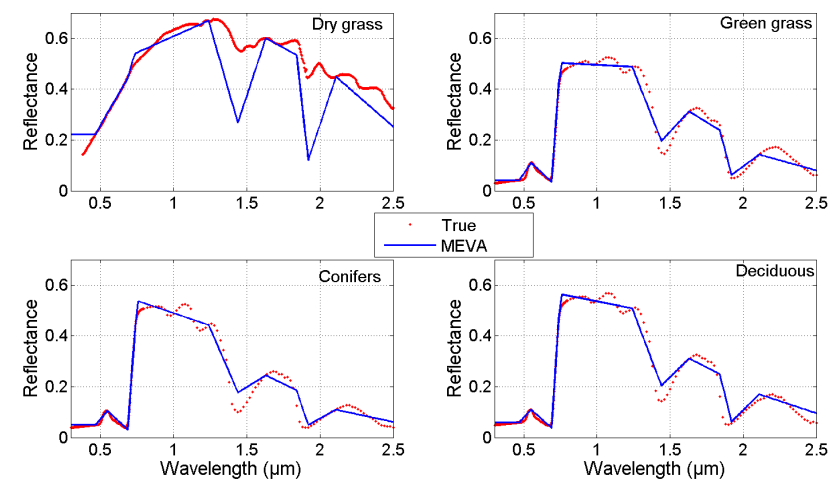

Fig. 7. The procedures for MEVA were applied to the reflectance spectra from the JHU spectral library for dry grass, green grass, conifer, and deciduous. The x-axis represents the wavelength from 0.3 to $2.5 \mu \mathrm{m}$; the $\mathrm{y}$-axis represents the reflectance; the dotted red curves represent the reflectance spectra from the JHU spectral library; the solid blue lines represent the MEVA results.

\subsection{Dry grass, green grass, conifer, and deciduous surfaces}

In this section, the studied vegetation types are dry grass, green grass, conifer, and deciduous; their reflectance spectra are provided by the JHU spectral library. Given reflectance at MODIS bands 1-7, the reflectance spectra are reconstructed through the methods discussed in the last section. Figure 7 shows the reflectance spectrum provided by the spectral library ("true") and MEVA. Though the dry grass case shows large differences between MEVA and the "true" spectrum, it was kept in all our calculations as an example of the "worst case" scenario and to demonstrate that even in this situation the fluxes and forcing errors are reasonably under control.

For each vegetation type, the outgoing solar flux at TOA and aerosol direct radiative forcing (from 0.3 to $2.5 \mu \mathrm{m}$ ) were calculated with the reflectance spectrum obtained from the high resolution spectral libraries ("true"), traditional approaches (the linear MODIS, the averaged band MODIS, the Liang visible and near infrared, the Liang shortwave), and the MEVA method. The results are summarized in Tables 1 and 2. As shown in Table 1, MEVA produces the outgoing flux that is closest to the "true" in all cases, with the difference varying from 0.58 to $1.31 \mathrm{~W} \mathrm{~m}^{-2}$, while the maximum deviation associated with other methods reaches $23 \mathrm{~W} \mathrm{~m}^{-2}$. A simplistic and naive expectation would be that the surface does not matter to aerosol forcing because the difference between two radiative fluxes would cancel out the impact of the surface reflectance. However this cancellation does not happen generally, because aerosol forcing depends on the balance among aerosol absorption, aerosol scattering, and surface reflectance. For example, some aerosols can have a cooling effect over low reflectance surfaces (e.g. vegetation), but have a warming effect over high reflectance surfaces (e.g. snow). With the exception of dry grass, Table 2 shows that 

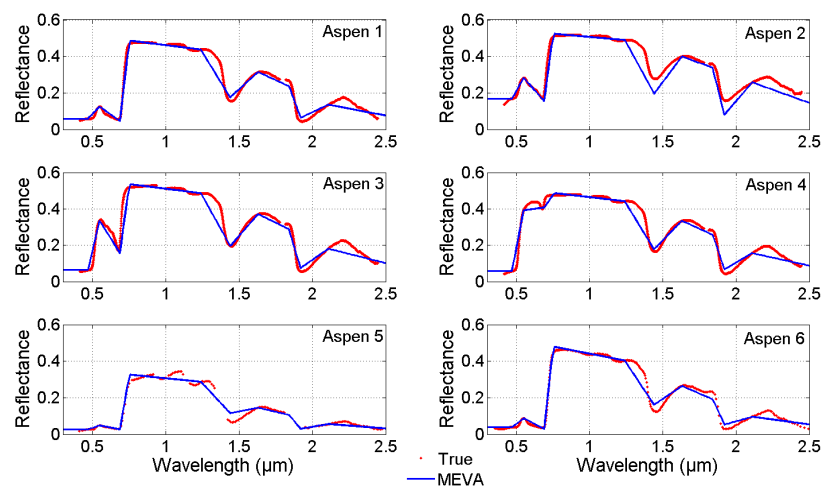

Fig. 8. In each subplot, the $x$-axis represents wavelength from 0.3 to $2.5 \mu \mathrm{m}$; the y-axis represents reflectance. The dotted red curves represent reflectance spectra for aspens from the USGS digital spectral library; the solid blue lines represent the MEVA results.

MEVA yields the aerosol forcing that is closest to the "true" case with regard to aerosol forcing magnitude (varying from 0.43 to $0.63 \mathrm{~W} \mathrm{~m}^{-2}$ ) and percentage (below $10 \%$ ). The exception of dry grass is explained in the following sensitivity discussion.

The sensitivity of aerosol DRF in different spectral ranges are investigated and shown in Table 3 for a deciduous vegetation surface. For the aerosol forcing in the spectral range of 0.55 to $1.24 \mu \mathrm{m}$, MEVA provides a difference of $0.35 \mathrm{~W} \mathrm{~m}^{-2}$ from the "true", as compared to differences between -1.41 to $-2.67 \mathrm{~W} \mathrm{~m}^{-2}$ from traditional approaches. This demonstrates that MEVA surpasses traditional approaches in calculating aerosol forcing. It can also be observed from Table 3 that the spectral range from 0.55 to $1.24 \mu \mathrm{m}$ presents the largest difference between each method and calculations with the "true" spectrum (except for the case of Liang shortwave). These results indicate the importance of filling the spectral gaps for the missing feature of the vegetation red edge around $0.7 \mu \mathrm{m}$, which is consistent with the discussion in Sect. 2.2. In the same fashion, gap filling through MEVA for the other missing features around 1.48 and $1.92 \mu \mathrm{m}$ lead to the closest aerosol forcing to "true", with differences of -0.03 and $0.01 \mathrm{~W} \mathrm{~m}^{-2}$, compared to the values from 0.01 to $0.08 \mathrm{~W} \mathrm{~m}^{-2}$ estimated through traditional approaches.

According to Table 3, the aerosol forcing differences for the gap filling of the vegetation water absorption missing features (shown in the spectral range of 1.24 to 1.63 and 1.84 to $2.1 \mu \mathrm{m}$ ) are smaller than the aerosol forcing difference obtained for the gap filling of the red edge missing feature (shown in the spectral range of 0.55 to $1.24 \mu \mathrm{m}$ ), i.e. 0.03 and 0.01 being smaller than $0.35 ; 0.01$ and 0.08 being smaller than 1.76 , etc. This result indicates that gap filling for the vegetation water absorption missing features has a relatively small impact on aerosol forcing calculation as compared to the impact from the missing red edge. This conclusion is well explained by the relatively weaker solar radiation
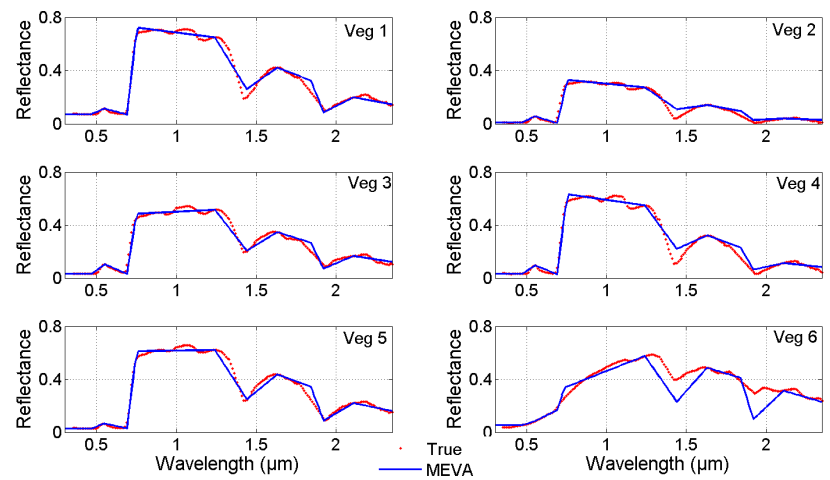

Fig. 9. In each subplot, the $x$-axis represents wavelength from 0.3 to $2.5 \mu \mathrm{m}$; the $\mathrm{y}$-axis represents reflectance. The solid blue lines represent the MEVA results; the dotted red curves represent the "true" reflectance spectra (adopted from Arai et al., 2010) for the following six Amazonia vegetation types: veg 1: manilkara Hubert; veg 2: couratari guianensis; veg 3: lecythis lurida; veg 4: genipa Americana; veg 5: miconia guianensis; and veg 6: litter.

and stronger atmospheric water absorption around $1.48 \mu \mathrm{m}$ and $1.92 \mu \mathrm{m}$ than those around $0.7 \mu \mathrm{m}$ as shown in Fig. 4a. This suggests that the results are not sensitive to the percentages we proposed in Fig. 5. Very similar results were derived in the analysis of green grass, conifer, aspens, and Amazon vegetation. The spectral analysis for dry grass indicates that the aerosol forcing difference of $1.84 \mathrm{~W} \mathrm{~m}^{-2}$ between MEVA and "true" (as in Table 2) is predominantly caused by the difference in the spectral range of 0.3 to $0.55 \mu \mathrm{m}$, where the difference is $1.86 \mathrm{~W} \mathrm{~m}^{-2}$ (compared to $0.17,-0.14,-0.01$, -0.01 , and -0.01 in the other five spectral ranges: 0.55 to $1.24,1.24$ to $1.63,1.63$ to $1.84,1.84$ to 2.1 and 2.1 to $2.5 \mu \mathrm{m}$ ). This might be related with the distinct spectral feature of dry grass in the range of the 0.3 to $0.55 \mu \mathrm{m}$ (as shown in Fig. 7). In Fig. 7, the spectral reflectance for green grass, conifers, and deciduous is characterized with a reflectance peak starting from about $0.5 \mu \mathrm{m}$ and ends at about $0.7 \mu \mathrm{m}$, which is absent from dry grass. This distinct spectral behavior by dry grass might be caused by its low chlorophyll and vegetation water content (Hoffer, 1978). In general, the results in Table 3 justify the gap-filling procedure by MEVA for the three missing features shown in Fig. 4.

\subsection{Aspen surfaces}

In this section, the above procedures are applied to the reflectance spectrum for aspen surfaces provided by the USGS digital spectral library (Clark et al., 2007). "Aspen 1" (green leaf), "aspen 2" (green leaf), "aspen 3" (yellow-green leaf), and "aspen 4" (yellow leaf) were sampled in Boulder, Colorado, USA, and their reflectances were measured by a laboratory spectrometer; "aspen 5" was sampled in Yellowstone National Park, Wyoming, USA, and its reflectance spectrum was retrieved from AVIRIS data; "aspen 6" was collected in 
Table 1. The calculated outgoing solar flux (in $\mathrm{W} \mathrm{m}^{-2}$; from 0.3 to $2.5 \mu \mathrm{m}$ ) at TOA over dry grass, green grass, conifer, and deciduous surfaces. Other parameters used include AOD (at $0.55 \mu \mathrm{m}$ ) of 0.32 , SSA (at $0.55 \mu \mathrm{m}$ ) of 0.89 , and SZA of 30 degrees. Bold numbers represent the difference in flux associated with different approaches to estimate the surface reflectance spectrum.

\begin{tabular}{lrrrr}
\hline Flux (in $\mathrm{W} \mathrm{m}^{-2}$ ) & Dry grass & Green grass & Conifer & Deciduous \\
\hline True & 362.17 & 237.18 & 234.99 & 251.21 \\
MEVA & 361.59 & 238.49 & 235.84 & 252.49 \\
Linear MODIS & 357.37 & 223.53 & 218.61 & 235.17 \\
Averaged band MODIS & 360.04 & 223.05 & 218.84 & 234.98 \\
Liang visible and near infrared & 352.63 & 221.03 & 218.42 & 235.96 \\
Liang shortwave & 363.12 & 213.79 & 212.33 & 229.96 \\
\hline Differences of flux (in $\mathrm{W} \mathrm{m}^{-2}$ ) & & & & \\
\hline MEVA - True & -0.58 & 1.31 & 0.85 & 1.28 \\
Linear MODIS - True & -4.8 & -13.65 & -16.38 & -16.04 \\
Average band MODIS - True & -2.13 & -14.13 & -16.15 & -16.23 \\
Liang visible and near infrared - True & -9.54 & -16.15 & -16.57 & -15.25 \\
Liang shortwave - True & 0.95 & -23.39 & -22.66 & -21.25 \\
\hline
\end{tabular}

Table 2. The calculated instantaneous aerosol direct radiative forcing (DRF, in $\mathrm{W} \mathrm{m}^{-2}$; from 0.3 to $2.5 \mu \mathrm{m}$ ) in clear-sky condition over dry grass, green grass, conifer, and deciduous surfaces. Other parameters used include AOD (at $0.55 \mu \mathrm{m}$ ) of 0.32 , SSA (at $0.55 \mu \mathrm{m})$ of 0.89 , and SZA of 30 degrees. Bold numbers represent the difference in aerosol forcing associated with different approaches to estimate surface reflectance spectrum. The numbers in parentheses indicate the ratio of the absolute difference to the aerosol forcing calculated with "true".

\begin{tabular}{lrrrr}
\hline DRF $\left(\right.$ in $\mathrm{W} \mathrm{m}^{-2}$ ) & Dry grass & Green grass & Conifer & Deciduous \\
\hline True & 14.28 & -8.25 & -7.86 & -6.28 \\
MEVA & 16.12 & -7.62 & -7.43 & -5.7 \\
Linear MODIS & 13.43 & -10.39 & -10.54 & -8.84 \\
Averaged band MODIS & 15.2 & -10.38 & -10.33 & -8.7 \\
Liang visible and near infrared & 17.72 & -9.88 & -10.07 & -8.06 \\
Liang shortwave & 27.03 & -0.46 & -0.74 & 2.66 \\
\hline Differences of DRF (in $\left.\mathrm{Wm}^{-2}\right)$ & & & & \\
\hline MEVA - True & $1.84(13 \%)$ & $0.63(8 \%)$ & $0.43(5 \%)$ & $0.58(9 \%)$ \\
Linear MODIS - True & $-0.85(6 \%)$ & $-2.14(26 \%)$ & $-2.68(34 \%)$ & $-2.56(41 \%)$ \\
Average band MODIS - True & $0.92(6 \%)$ & $-2.13(26 \%)$ & $-2.47(31 \%)$ & $-2.42(39 \%)$ \\
Liang visible and near infrared - True & $3.44(24 \%)$ & $-1.63(20 \%)$ & $-2.21(28 \%)$ & $-1.78(28 \%)$ \\
Liang shortwave - True & $12.75(89 \%)$ & $7.79(94 \%)$ & $7.12(91 \%)$ & $8.94(142 \%)$ \\
\hline
\end{tabular}

Denver, Colorado, USA, and its reflectance spectrum is the average of the three measured spectra. Figure 8 shows the reflectance spectra from "true" and MEVA for these six different aspen surfaces.

The outgoing flux at TOA and aerosol forcing were calculated using these reflectance spectra as surface albedo, and the results are shown in Tables 4 and 5. With the exception of aspen 4, MEVA leads to the minimum difference to "true" for both flux and aerosol forcing compared to traditional approaches. The aerosol forcing difference between MEVA and "true" is $0.61 \mathrm{~W} \mathrm{~m}^{-2}$ for aspen 4 , which is greater than the difference of $-0.36 \mathrm{~W} \mathrm{~m}^{-2}$ from the average band MODIS method. This might be related with the leaf color being "yellow", which implies strong reflectance in the range of 0.57 to $0.59 \mu \mathrm{m}$ as seen in Fig. 8. Similar to the spectral behavior of dry grass, the spectral behavior of aspen 4 might be caused by its low chlorophyll and water moisture content (Hoffer, 1978). This indicates that MEVA works best for green vegetation types, but still produces reasonable results for yellow leaves. Overall, MEVA consistently improves the accuracy of the calculated outgoing flux at TOA and aerosol forcing.

\subsection{Amazon vegetation}

Results for Amazonian vegetation are specifically investigated in this section. The Amazon forest plays a unique role in climate change (Shukla et al., 1990; Nobre et al., 1991). However, Amazon vegetation reflectance data is scarce (Roberts et al., 1990; Arai et al., 2010). The reflectance spectrum for six Amazon vegetation types from 
Table 3. The calculated instantaneous aerosol DRF (in $\mathrm{W} \mathrm{m}^{-2}$ ) in different spectral ranges over deciduous surface. Other parameters used include: AOD $($ at $0.55 \mu \mathrm{m})=0.32$; SSA $($ at $0.55 \mu \mathrm{m})=0.89$; and SZA $=30$ degrees. Bold numbers represent the differences in aerosol forcing between applying specific approaches and "true" in specified spectral ranges.

\begin{tabular}{lrrrrrr}
\hline DRF (in W m $^{-2}$ ) & $0.3-0.55 \mu \mathrm{m}$ & $0.55-1.24 \mu \mathrm{m}$ & $1.24-1.63 \mu \mathrm{m}$ & $1.63-1.84 \mu \mathrm{m}$ & $1.84-2.1 \mu \mathrm{m}$ & $2.1-2.5 \mu \mathrm{m}$ \\
\hline True & -10.25 & 3.37 & 0.47 & 0.11 & 0 & 0.02 \\
MEVA & -9.99 & 3.72 & 0.44 & 0.11 & 0.01 & 0.02 \\
Linear MODIS & -11.13 & 1.61 & 0.55 & 0.1 & 0.01 & 0.01 \\
Averaged band MODIS & -10.07 & 0.7 & 0.53 & 0.11 & 0.01 & 0.02 \\
Liang visible and near infrared & -10.31 & 1.41 & 0.55 & 0.17 & 0.04 & 0.08 \\
Liang shortwave & 0.4 & 1.96 & 0.17 & 0.07 & 0.01 & 0.03 \\
\hline Difference of DRF (in W m ${ }^{-2}$ ) & & & & & & \\
\hline MEVA - True & 0.26 & 0.35 & -0.03 & 0 & 0.01 & 0 \\
Linear MODIS - True & -0.88 & -1.76 & 0.08 & -0.01 & 0.01 & -0.01 \\
Average band MODIS - True & 0.18 & -2.67 & 0.06 & 0 & 0.01 & 0 \\
Liang visible and near infrared - True & -0.06 & -1.96 & 0.08 & 0.06 & 0.04 & 0.06 \\
Liang shortwave - True & 10.65 & -1.41 & -0.3 & -0.04 & 0.01 & 0.01 \\
\hline
\end{tabular}

Table 4. The calculated integration of the outgoing solar flux (in $\mathrm{W} \mathrm{m}^{-2}$; from 0.3 to $2.5 \mu \mathrm{m}$ ) at TOA over aspen surface. Other parameters used in the calculation include AOD (at $0.55 \mu \mathrm{m}$ ) of 0.32 ; SSA (at $0.55 \mu \mathrm{m}$ ) of 0.89 ; and SZA of 30 degrees. Bold numbers represent the difference of the flux associated with applying different approaches to estimate the reflectance spectrum.

\begin{tabular}{|c|c|c|c|c|c|c|}
\hline Flux (in $\mathrm{W} \mathrm{m}^{-2}$ ) & Aspen 1 & Aspen 2 & Aspen 3 & Aspen 4 & Aspen 5 & Aspen 6 \\
\hline True & 235.81 & 296.29 & 291.82 & 302.30 & 172.65 & 218.16 \\
\hline MEVA & 234.74 & 292.37 & 284.38 & 300.04 & 174.18 & 219.67 \\
\hline Linear MODIS & 219.98 & 277.69 & 273.17 & 296.36 & 164.42 & 204.73 \\
\hline Averaged band MODIS & 220.86 & 282.53 & 273.93 & 298.44 & 163.87 & 204.91 \\
\hline Liang visible and near infrared & 218.08 & 278.32 & 263.25 & 277.86 & 162.01 & 202.83 \\
\hline Liang shortwave & 208.10 & 252.65 & 219.64 & 253.95 & 165.69 & 198.23 \\
\hline \multicolumn{7}{|l|}{ Differences of flux (in $\mathrm{W} \mathrm{m}^{-2}$ ) } \\
\hline MEVA - True & -1.07 & -3.92 & -7.44 & -2.26 & 1.53 & 1.51 \\
\hline Linear MODIS - True & -15.83 & -18.60 & -18.65 & -5.94 & -8.23 & -13.43 \\
\hline Average band MODIS - True & -14.95 & -13.76 & -17.89 & -3.86 & -8.78 & -13.25 \\
\hline Liang visible and near infrared - True & -17.73 & -17.97 & -28.57 & -24.44 & -10.64 & -15.33 \\
\hline Liang shortwave - True & -27.71 & -43.64 & -72.18 & -48.35 & -6.96 & -19.93 \\
\hline
\end{tabular}

Arai et al. (2010) were shown in Fig. 9, overlaid with their MEVA spectra. The spectra from Arai et al. did not show the reflectance value in the range of 1.35 to $1.45 \mu \mathrm{m}$ and 1.85 to $1.95 \mu \mathrm{m}$, which were linearly connected in this study to represent "true".

In a more detailed analysis, the outgoing flux at TOA and aerosol forcing were calculated with three biomass burning aerosol models having different absorption as shown in Fig. 10. In Fig. 10, the SSA curves are simulated from Mie code (Wiscombe, 1980) with 1.4589 as the real part of the refractive index and three cases of spectrally constant imaginary refractive index equal to $0.0073,0.0173$, and 0.0273 . According to aerosol optical properties studies (e.g. Dubovik et al., 2002; Eck et al., 2003), biomass burning aerosols have a relatively spectrally constant imaginary refractive index. This simplification has also been applied to the biomass burning aerosol study by Procopio et al. (2003). The size distribution was calculated through the Amazonian forest aerosol model by Dubovik et al. (2002).

Aerosol forcing efficiency (defined as aerosol direct radiative forcing per unit AOD) results calculated with SSA (at $0.55 \mu \mathrm{m})=0.95$ (noted as "model 1"), 0.89 (noted as "model 2 "), and 0.83 (noted as "model 3") for Amazon vegetation types are presented in Fig. 11. Other parameters used in these calculations include AOD (at $0.55 \mu \mathrm{m})=0.32$ and SZA $=30$ degrees. The results in Fig. 11 show that MEVA yields an aerosol forcing efficiency (in $\mathrm{W} \mathrm{m}^{-2} \mathrm{AOD}^{-1}$ ) closest to that provided by "true" surface albedo. Using broadband shortwave albedo could introduce an error of 10 to $50 \mathrm{~W} \mathrm{~m}^{-2}$ $\mathrm{AOD}^{-1}$. Similar to the earlier results for green grass, canopy, deciduous, and aspens, the results for Amazon vegetation also indicate that the MEVA algorithm leads to the best 
Table 5. The calculated instantaneous aerosol DRF (in $\mathrm{W} \mathrm{m}^{-2}$; from 0.3 to $2.5 \mu \mathrm{m}$ ) over aspen surfaces. Other parameters used in the calculation include AOD (at $0.55 \mu \mathrm{m}$ ) of 0.32 ; SSA (at $0.55 \mu \mathrm{m}$ ) of 0.89 ; and SZA of 30 degrees. Bold numbers represent the differences of aerosol forcing associated with applying different approaches and "true"; the numbers in parentheses represent the ratio of the absolute difference in aerosol forcing to the results calculated with "true".

\begin{tabular}{|c|c|c|c|c|c|c|}
\hline $\mathrm{DRF}$ (in $\mathrm{W} \mathrm{m}^{-2}$ ) & Aspen 1 & Aspen 2 & Aspen 3 & Aspen 4 & Aspen 5 & Aspen 6 \\
\hline MEVA & -6.90 & 6.11 & 2.58 & 6.93 & -15.09 & -9.73 \\
\hline Averaged band MODIS & -9.43 & 4.21 & 0.44 & 5.96 & -16.99 & -12.37 \\
\hline Liang visible and near infrared & -9.18 & 4.30 & 1.01 & 7.89 & -17.05 & -12.17 \\
\hline Liang shortwave & -1.57 & 6.98 & 0.67 & 7.23 & -9.95 & -3.49 \\
\hline MEVA - True & $0.38(5 \%)$ & $0.32(6 \%)$ & $-0.46(15 \%)$ & $0.61(10 \%)$ & $0.56(4 \%)$ & $0.64(6 \%)$ \\
\hline Linear MODIS - True & $-2.60(36 \%)$ & $-3.86(67 \%)$ & $-2.81(92 \%)$ & $-1.01(16 \%)$ & $-1.30(8 \%)$ & $-2.10(20 \%)$ \\
\hline Average band MODIS - True & $-2.15(30 \%)$ & $-1.58(27 \%)$ & $-2.60(86 \%)$ & $-0.36(6 \%)$ & $-1.34(9 \%)$ & $-2.00(19 \%)$ \\
\hline Liang visible and near infrared - True & $-1.90(26 \%)$ & $-1.49(26 \%)$ & $-2.03(67 \%)$ & $1.57(25 \%)$ & $-1.40(9 \%)$ & $-1.80(17 \%)$ \\
\hline Liang shortwave - True & $5.71(78 \%)$ & $1.19(21 \%)$ & $-2.37(78 \%)$ & $0.91(14 \%)$ & $5.70(36 \%)$ & $6.88(66 \%)$ \\
\hline
\end{tabular}

Table 6. The calculated daily average aerosol DRF at equator and in equinox (in $\mathrm{W} \mathrm{m}^{-2}$; from 0.3 to $2.35 \mu \mathrm{m}$ ) with different approaches to the surface reflectance spectrum. The last column presents the average aerosol forcing over the six vegetation types. Bold numbers indicate the differences in daily averaged aerosol forcing associated with different approaches; the numbers in parentheses represent the ratio of these differences to the results calculated with "true". Other parameters used in the simulation include SSA (at 0.55 $\mu \mathrm{m}$ ) of 0.89 and AOD (at $0.55 \mu \mathrm{m})$ of 0.32 .

\begin{tabular}{|c|c|c|c|c|c|c|c|}
\hline Daily average DRF (in $\mathrm{W} \mathrm{m}^{-2}$ ) & Veg 1 & Veg 2 & Veg 3 & Veg 4 & Veg 5 & Veg 6 & $\begin{array}{l}\text { Average over the } \\
\text { six vegetation }\end{array}$ \\
\hline True & -2.65 & -8.68 & -5.42 & -4.80 & -4.94 & -5.25 & -5.29 \\
\hline MEVA & -2.56 & -8.68 & -5.51 & -4.73 & -4.94 & -5.04 & -5.24 \\
\hline Linear MODIS & -3.91 & -9.35 & -6.54 & -5.94 & -6.09 & -5.60 & -6.24 \\
\hline Averaged band MODIS & -4.03 & -9.50 & -6.63 & -6.14 & -6.34 & -5.63 & -6.38 \\
\hline Liang visible and near infrared & -3.61 & -9.57 & -6.37 & -5.91 & -5.78 & -4.85 & -6.02 \\
\hline Liang shortwave & 2.21 & -7.32 & -2.66 & -1.14 & 0.02 & -0.07 & -1.49 \\
\hline \multicolumn{8}{|c|}{ Difference of daily average DRF (in $\mathrm{W} \mathrm{m}^{-2}$ ) } \\
\hline MEVA - True & 0.09 & 0.00 & -0.09 & 0.07 & 0.00 & 0.21 & $0.05(-0.9 \%)$ \\
\hline Linear MODIS - True & -1.26 & -0.67 & -1.12 & -1.14 & -1.15 & -0.36 & $-0.95(18.0 \%)$ \\
\hline Average band MODIS - True & -1.38 & -0.81 & -1.21 & -1.34 & -1.40 & -0.38 & $-1.09(20.6 \%)$ \\
\hline Liang visible and near infrared - True & -0.96 & -0.89 & -0.95 & -1.11 & -0.84 & 0.39 & $-0.73(13.8 \%)$ \\
\hline Liang shortwave - True & 4.86 & 1.37 & 2.76 & 3.66 & 4.96 & 5.17 & $3.80(-71.8 \%)$ \\
\hline
\end{tabular}

approximation to the "true" surface albedo spectra, regarding the accuracy of the outgoing flux at TOA and the aerosol direct forcing.

Moreover, the differences of the aerosol forcing efficiency associated with different methods to estimate reflectance spectrum are averaged over the six Amazonian vegetation types studied here. The results in Fig. 12 indicate that the aerosol forcing efficiency calculated through MEVA is the closest to that from "true" than the other traditional approaches discussed here. The same conclusion is drawn from the studies with AODs equal to 0.64 and 1.28 (at $0.55 \mu \mathrm{m}$ ).

To assess the impacts of surface spectral albedo approximations on the daily average aerosol forcing, we per- form the aerosol forcing calculations at the Equator and in equinox condition. The surface albedo is assumed to be SZAindependent. Figure 13 indicates that MEVA yields aerosol forcing closest to that from "true" than traditional approaches for all vegetation types and under all SZAs (especially when SZA is smaller than 60 degrees). The daily averaged aerosol forcing was determined by the $24 \mathrm{~h}$ average aerosol forcing. Table 6 shows that MEVA produces a daily average aerosol forcing closest to that from "true" compared to traditional approaches for all vegetation types. We also average the daily average aerosol forcing at Equator at equinox over the studied six vegetation types. The results, shown in the last column of Table 6, indicate that MEVA is the best approximation to 

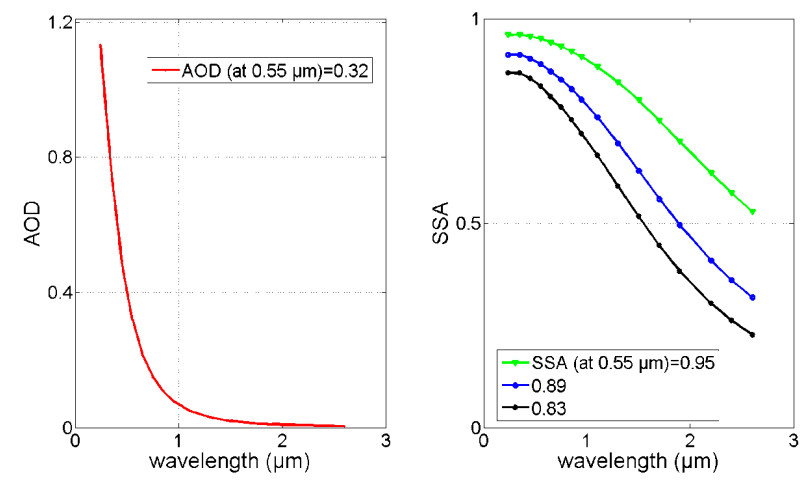

Fig. 10. The plot on the left shows the wavelength dependence of AOD for the aerosol models used in the TOA flux and aerosol forcing calculations; the plots on the right display three different aerosol models used in the flux and aerosol forcing calculations: SSA (at $0.55 \mu \mathrm{m})=0.95,0.89$, and 0.83 .

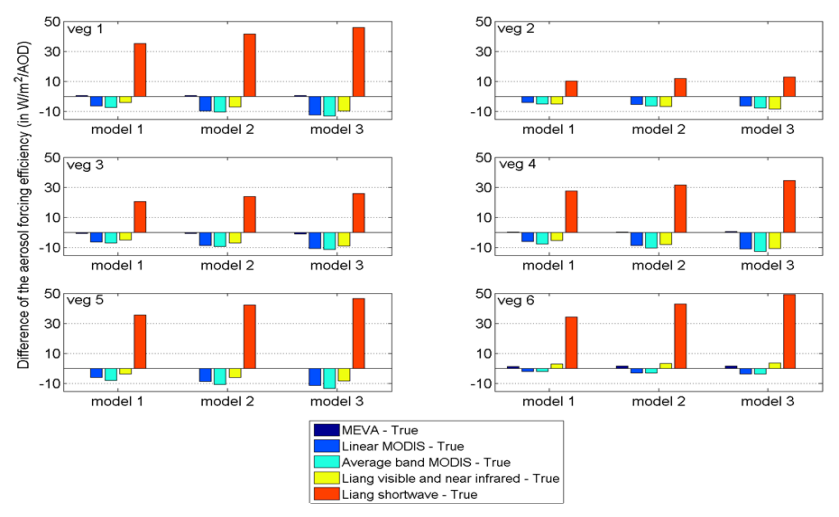

Fig. 11. Difference of the aerosol forcing efficiency (in $\mathrm{W} \mathrm{m}^{-2} \mathrm{AOD}^{-1}$ ) associated with different approaches to estimate reflectance spectra for vegetation types shown in Fig. 9. In each subplot, three groups indicate the results caused by using three different aerosol models shown in Fig. 10: SSA (at $0.55 \mu \mathrm{m})=0.95$ (noted as "model 1"), 0.89 (noted as "model 2"), and 0.83 (noted as "model 3"). Other parameters used in the calculations include AOD $($ at $0.55 \mu \mathrm{m})=0.32$ and $\mathrm{SZA}=30$ degrees.

the "true" case using the high resolution surface reflectance spectrum. The magnitude of the average aerosol forcing difference between MEVA and "true" is about $0.05 \mathrm{~W} \mathrm{~m}^{-2}$, much smaller than $-0.95,-1.09,-0.73$, and $3.80 \mathrm{~W} \mathrm{~m}^{-2}$ calculated using traditional approaches. The magnitude of the ratio of this difference to that from "true" is also the minimum at $-0.9 \%$ compared to $18.0 \%, 20.6 \%, 13.8 \%$, and $-71.8 \%$ estimated through traditional approaches. A similar investigation was done with different aerosol models: SSA (at $0.55 \mu \mathrm{m})=0.95$ and 0.83 ; AOD (at $0.55 \mu \mathrm{m})=0.64$ and 1.28. Consistently, the results show that MEVA yields average aerosol forcing closest to that from "true" compared with traditional approaches.

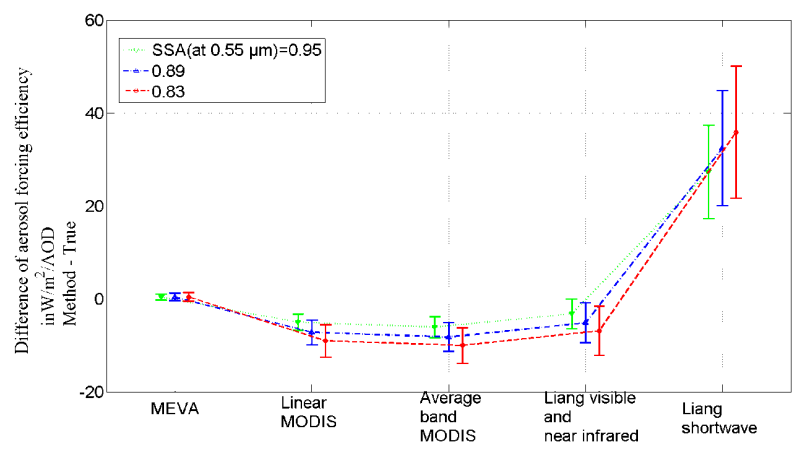

Fig. 12. The difference of aerosol forcing efficiency derived from averaging the results shown in Fig. 11 over the six Amazonian vegetation types. Bars represent the standard deviation of the aerosol forcing efficiency differences among the six vegetation types. The labels on the $\mathrm{x}$-axis denote different methods to estimate vegetation reflectance spectrum used in the aerosol forcing calculation. The curves in green, blue, and red represent the results for different aerosol models: SSA $($ at $0.55 \mu \mathrm{m})=0.95,0.89$, and 0.83 . Other parameters used include AOD (at $0.55 \mu \mathrm{m}$ ) of 0.32 and SZA of 30 degrees.
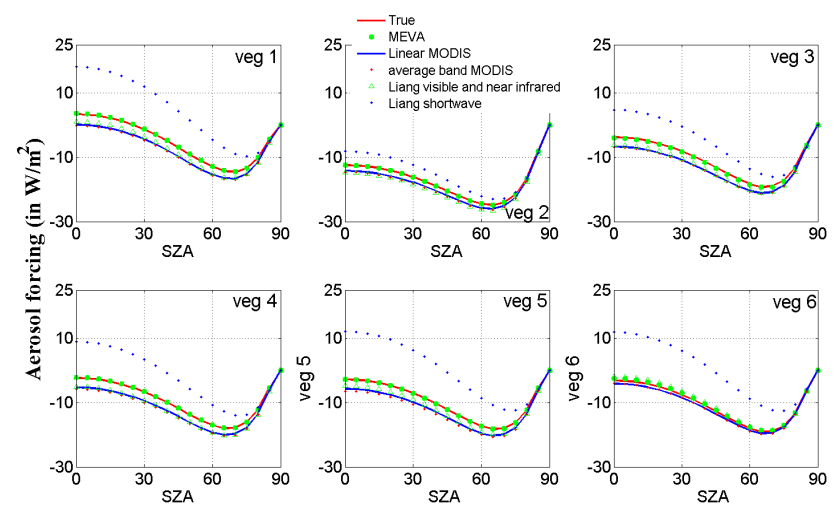

Fig. 13. Aerosol forcing when SZA varies from 0 to 90 degrees for vegetation types shown in Fig. 9. Curves in different symbols are associated with different approaches to estimate vegetation reflectance spectrum used in the aerosol forcing calculation. Other parameters used in the calculations include AOD (at $0.55 \mu \mathrm{m}$ ) of 0.32 and SSA (at $0.55 \mu \mathrm{m}$ ) of 0.89 .

\section{Conclusions}

In this research, a new approach called MEVA was developed to estimate the continuous vegetation reflectance spectrum using the reflectance measurements acquired from MODIS seven bands, namely $0.47,0.55,0.67,0.86,1.24$, 1.63 , and $2.11 \mu \mathrm{m}$. The approach enhances the MODIS vegetation albedo product by characterizing large spectral variation features at $0.7,1.44$, and $1.92 \mu \mathrm{m}$ that are missing in the MODIS observations. Several sources of vegetation spectral reflectance were used to evaluate the MEVA approach: the JHU spectral library (for dry grass, green grass, conifer, 
and deciduous surfaces), the USGS digital spectral library (for aspen surface), and measurements of six Amazon vegetation types. The gap filling for the missing red edge feature at $0.7 \mu \mathrm{m}$ is the most significant due to the strong solar radiation input in this spectral range; the other two gap fillings for vegetation water absorption signatures are less important, due to the weaker solar radiation and strong atmospheric water absorption.

Flux and aerosol forcing calculation results indicate that MEVA has significant advantages over traditional approaches in accurately calculating radiative fluxes and aerosol radiative forcing. For the studied cases with AOD (at $0.55 \mu \mathrm{m}$ ) $=0.32$, MEVA improved the accuracy of the outgoing flux at TOA by up to $60 \mathrm{~W} \mathrm{~m}^{-2}$ (nearly $20 \%$ of the flux value derived from "true"), aerosol forcing by up to $10 \mathrm{~W} \mathrm{~m}^{-2}$ (about $70 \%$ of the forcing value derived from "true"), daily averaged aerosol forcing at equator at equinox by up to $3.7 \mathrm{~W} \mathrm{~m}^{-2}$ (about $70 \%$ of the forcing value derived from "true"). A similar conclusion was drawn from parallel studies applying AOD (at $0.55 \mu \mathrm{m})=0.64$ and 1.28 . For aerosol forcing, MEVA led to errors less than $1 \mathrm{~W} \mathrm{~m}^{-2}$ with the exception of dry grass, which produced an error of $1.84 \mathrm{~W} \mathrm{~m}^{-2}$. This greater error might be associated with lower chlorophyll and water content of dry grass compared with the other discussed vegetation types. The combination of MEVA results with our retrievals of SSA for biomass burning aerosols (Zhu et al., 2011) will improve the estimate of radiative forcing and their impacts on climate by providing more accurate flux and aerosol forcing calculations.

Our exercise in this study shows that MEVA can be employed to improve the accuracy of flux and aerosol forcing calculations for vegetated surfaces. Particularly with the publicly available global surface albedo data at MODIS seven channels, MEVA can be integrated into radiative transfer calculations and contribute to regional climate studies over vegetated areas. In this study, the MEVA algorithm validation used laboratory measurements of leaf reflectance as land surface albedo in radiative transfer simulations. This work can be further improved with the analysis of real remote sensing data where individual pixels might be composed of mixed different land and vegetation types including yellow leaves.

Acknowledgements. We would like to thank NASA for funding this project under the grant NNX08AJ78G and IDS project, managed by H. Maring. We also would like to thank the MODIS team for their excellent work on the instrument development, maintenance, and calibration. We thank their effort on data quality control and providing data to the public as well. Thanks also go to Elisa Thome Sena for her constructive comments and suggestions.

Edited by: P. Stammes

\section{References}

Arai, E., Pereira, G., Coura, S. M. C., Cardozo, F. S., Silva, F. B., Shimabukuro, Y. E., Moraes, E. C., Freitsa, R. M., and EspiritoSanto, F. D. B.: Spectral signature of leaves of Amazon rainforest tree species, IGARSS, 2011 IEEE International, 4788-4791, 2010.

Asner, G. P., Wessman, C. A., Bateson, C. A., and Privette, J. L.: Impact of tissue, canopy, and landscape factors on the hyperspectral reflectance variability of arid ecosystems, Remote Sens. Environ., 74, 69-84, 2000.

Betts, R. A.: Offset of the potential carbon sink from boreal forestation by decreases in surface albedo, Nature, 408, 187-190, 2000

Ceccato, P., Flasse, S., Tarantola, S., Jacquemoud, S., and Gregoire, J. M.: Detecting vegetation leaf water content using reflectance in the optical domain, Remote Sens. Environ., 77, 22-33, 2001.

Cess, R. D.: Biosphere-albedo feedback and climate modeling, J. Atmos. Sci., 35, 1765-1767, 1978.

Clark, R. N., Swayze, G. A., Wise, R., Livo, E., Hoefen, T., Kokaly, R., and Sutley, S. J.: USGS digital spectral library splib06a: US Geological Survey, Digital Data Series 231, http://speclab. cr.usgs.gov/spectral.lib06 (last access: November 2012), 2007.

Collins, W.: Remote sensing of crop type and maturity, Engineering, 44, 43-55, 1978.

Dickinson, R. E.: Land surface processes and climate-Surface albedos and energy balance. Advances in Geophysics, 25, 305-353, Theory of Climate, Academic Press Inc. Published by Elsevier Ltd, 1983.

Dickinson, R. E.: Land processes in climate models, Remote Sens. Environ., 51, 27-38, 1995.

Diner, D.: Level 2 surface retrieval algorithm theoretical basis, JPL 11401, Revision E, 2008.

Dirmeyer, P. A. and Shukla, J.: The response of the general circulation to deforestation in the tropics, American Meteorology Society, Proc., 5th Symposium on Global Change, 131-134, 1994.

Dubovik, O., Holben, B. N., Eck, T. F., Smirnov, A., Kaufman, Y. J., King, M. D., Tanré, D., and Slutsker, I.: Variability of absorption and optical properties of key aerosol types observed in worldwide locations, J. Atmos. Sci., 59, 590-608, 2002.

Eck, T. F., Holben, B. N., Ward, D. E., Mukelabai, M. M., Dubovik, O., Smirnov, A., Schafer, J. S., Hsu, N. C., Piketh, S. J., Queface, A., Le Roux, J., Swap, R. J., and Slutsker, I.: Variability of biomass burning aerosol optical characteristics in southern Africa during the SAFARI 2000 dry season campaign and a comparison of single scattering albedo estimates from radiometric measurements, J. Geophys. Res., 108, 8477, doi:10.1029/2002JD002321, 2003.

Gilgen, H., Whitlock, C., Koch, F., Müller, G., Ohmura, A., Steiger, D., and Wheeler, R.: Technical Plan for BSRN (Baseline Surface Radiation Network) Data Management, Version 2.1 (final), MO/TD-No. 443, WCRP/WMO, 1995.

Gitelson, A. A., Merzlyak, M. N., and Lichtenthaler, H. K.: Detection of red edge position and Chlorophyll content by reflectance measurements near $700 \mathrm{~nm}$, J. Plant Physiol., 148, 501-508, 1996.

Guyot, G., Baret, F., and Jacquemoud, S.: Imaging spectroscopy for vegetation studies, Imaging Spectroscopy: Fundamentals and Prospective Applications, in: Remote Sensing, Volume 2, edited by: Toselli, F. and Bodechtel, J., Kluwer Academic Publishers, 145-165, 1992. 
Hall, F. G. and Sellers, P. J.: First International Satellite Land Surface Climatology Project (ISLSCP) Field Experiment (FIFE) in 1995, J. Geophys. Res., 100, 25383-25395, doi:10.1029/95JD03300, 1995.

Hoffer, R. M.: Biological and physical considerations in applying computer-aided analysis techniques to remote sensing data, in: Remote Sensing: The Quantitative Approach, edited by: Swain, P. H. and Davis, S. M., McGraw-Hill, 227-289, 1978.

Horler, D. N. H., Dockray, M., and Barber, J.: The red edge of plant leaf reflectance, Int. J. Remote Sens., 1, 121-136, 1983.

Hosgood, B., Jacquemoud, S., Andreoli, G., Verdebout, J., Pedrini, A., and Schmuck, G.: Leaf Optical Properties EXperiment 93 (LOPEX93), Report EUR 16095 EN, 1994.

Kim, M. S., Daughtry, C. S., Chappelle, E. W., Mcmurtrey, J. E., and Walthall, C. L.: The use of high spectral resolution bands for estimating absorbed photonsynthetically active radiation (A PAR), in: Proceedings of the 6th Symposium on Physical Measurements and Signatures in Remote Sensing, Val D'Isere, France, 17-21 January, 299-306, 1994.

Koelemeijer, R. B. A., de Haan, J. F., and Stammes, P.: A database of spectral surface reflectivity in the range 335-772 nm derived from 5.5 years of GOME observations, J. Geophys. Res., 108, 4070, doi:10.1029/2002JD002429, 2003.

Leroy, M., Deuze, J. L., Breon, F. M., Hautecoeur, O., Herman, M., Buriez, J. C., Tanre, D., Bouffies, S., Chazette, P., and Roujean, J. L.: Retrieval of atmospheric properties and surface bidirectional reflectances over land from POLDER/ADEOS, J. Geophys. Res., 102, 17023-17037, 1997.

Liang, S., Strahler, A. H., and Walthall, C.: Retrieval of land surface albedo from satellite observations: a simulation study, J. Appl. Meteorol., 38, 712-725, 1999.

Lofgren, B. M.: Surface albedo-climate feedback simulated using two-way coupling, J. Climate, 8, 2543-2562, 1995.

Lucht, W., Schaaf, C. B., and Strahler, A. H.: An algorithm for the retrieval of albedo from space using semiempirical BRDF models, IEEE Geosci. Remote S., 38, 977-998, 2000.

Lucht, W., Prentice, I. C., Myneni, R. B., Sitch, S., Friedlingstein, P., Cramer, W., Bousquet, P., Buermann, W., and Smith, B.: Climatic control of the high-latitude vegetation greening trend and pinatubo effect, Science, 296, 1687-1689, doi:10.1126/science.1071828, 2002.

Lyapustin, A. I.: Atmospheric and geometrical effects on land surface albedo, J. Geophys. Res., 104, 4127-4143, doi:10.1029/1998JD200064, 1999.

McComiskey, A., Schwartz, S. E., Schmid, B., Guan, H., Lewis, E. R., Ricchiazzi, P., and Ogren, J. A.: Direct aerosol forcing: Calculation from observables and sensitivities to inputs, J. Geophys. Res., 113, D09202, doi:10.1029/2007JD009170, 2008.

Moody, E. G., King, M. D., Platnick, S., Schaaf, C. B., and Gao, F.: Spatially complete global spectral surface albedos: value-added datasets derived from Terra MODIS land products, IEEE Geosci. Remote S., 43, 144-158, 2005.

Muller, J.-P.: MERIS GLOBAL LAND SURFACE ALBEDO MAPS: Algorithm Theoretical Basis Document ATBD 1.4 BRDF/ALBEDO RETRIEVAL, available at: http://www.brockmann-consult.de/albedomap/pdf/ MERIS-AlbedoMap-ATBD_BRDF_Albedo-1.0.pdf (last access: May 2012), 2006.
Myhre, G., Kvalevåg, M. M., and Schaaf, C. B.: Radiative frocing due to anthropogenic vegetation change based on MODIS surface albedo data, Geophys. Res. Lett., 32, L21410, doi:10.1029/2005GL024004, 2005.

Nobre, C. A., Sellers, P. S., and Shukla, J.: Amazonian deforestation and regional climate change, J. Climate, 4, 957-988, 1991.

Patadi, F., Yang, E.-S., and Christopher, S. A.: Does dust change the clear sky top of atmosphere shortwave flux over high surface reflectance regions? Geophys. Res. Lett., 36, L15825, doi:10.1029/2009GL039092, 2009.

Popp, C., Wang, P., Brunner, D., Stammes, P., Zhou, Y., and Grzegorski, M.: MERIS albedo climatology for FRESCO $+\mathrm{O}_{2}$ A-band cloud retrieval, Atmos. Meas. Tech., 4, 463-483, doi:10.5194/amt-4-463-2011, 2011.

Procopio, A. S., Remer, L. A., Artaxo, P., Kaufman, Y. J., and Holben, B. N.: Modeled spectral optical properties for smoke aerosols in Amazonia, Geophys. Res. Lett., 30, 2265, doi:10.1029/2003GL018063, 2003.

Ricchiazzi, P., Yang, S., Gautier, C., and Sowle, D.: SBDART: A research and teaching software tool for plane-parallel radiative transfer in the Earth's atmosphere, B. Am. Meteorol. Soc., 79, 2101-2114, 1998.

Roberts, D. A., Nelson, B. W., Adams, J. B., and Palmer, F.: Spectral changes with leaf aging in Amazon caatinga, Trees - Structure and Function, 12, 315-325, doi:10.1007/s004680050157, 1990.

Saunders, R. W.: The determination of broad band surface albedo from AVHRR visible and near-infrared radiances, Int. J. Remote Sens., 11, 49-67, 1990.

Schaaf, C. B., Gao, F., Strahler, A. H., Lucht, W., Li, X., and Tsnag, T.: First operational BRDF, albedo nadir reflectance products from MODIS, Remote Sens. Environ., 83, 135-148, 2002.

Sei, A: Joint Polar Satellite System (JPSS) VIIRS surface albedo algorithm theoretical basis document (ATBD), GSFC JPSS CMO 474-00040, available at: http: //npp.gsfc.nasa.gov/science/sciencedocuments/ATBD_122011/ 474-00040_VIIRS_Surface_Albedo_ATBD_Rev-_20110422.pdf (last access: November 2012), 2011.

Sellers, P. J., Hall, F. G., Asrar, G., Strebel, D. E., and Murphy, R. E.: An overview of the First International Satellite Land Surface Climatology Project (ISLSCP) Field Experiment (FIFE), J. Geophys. Res., 97, 18355-18371, 1992.

Shukla, J., Nobre, C., and Sellers, P.: Amazon Deforestation and climate change, Science, 247, 1322-1325, doi:10.1126/science.247.4948.1322, 1990.

Sims, D. A. and Gamon, J. A.: Relationship between leaf pigment content and spectral reflectance across a wide range of species, leaf structures and developmental stages, Remote Sens. Environ., 81, 337-354, 2002.

Staenz, K., Williams, D. J., and Walker, B.: Surface reflectance retrieval from AVIRIS data using a six dimensional look up table, in: Summaries of the Sixth Annual JPL Earth Science Workshop, Jet Propulsion Laboratory, Pasadena, CA, 223-230, 1996.

Stimson, H. C., Breshears, D. D., Ustin, S. L., and Kefauver, S. C.: Spectral sensing of folier water conditions in two co-occuring conifer species: Pinus edulis and Juniperus monosperma, Remote Sens. Environ., 96, 108-118, 2005.

Vermote, E. F, Saleous, N. E., Justice, C. O., Kaufman, Y. J., Privette, J. L., and Remer, L.: Atmospheric correction of visible to middle-infrared EOS-MODIS data over land surfaces: 
Background, operational algorithm and validation, J. Geophys. Res., 102, 17131-17141, doi:10.1029/97JD00201, 1997.

Wang, P., Knap, W. H., and Stammes, P.: Cloudy sky shortwave radiative closure for a Baseline Surface Radiation Network site, J. Geophys. Res., 116, D08202, doi:10.1029/2010JD015141, 2011.

Wiscombe, W. J.: Improved Mie scattering algorithm, Appl. Optics, 19, 1505-1509, 1980.

Yu, H., Dickinson, R. E., Chin, M., Kaufman, Y. J., Zhou, M., Zhou, L., Tian, Y., Dubovik, O., and Holben, B. N.: The direct radiative effect of aerosols as determined from a combination of MODIS retrievals and GOCART simulations, J. Geophys. Res., 109, D03206, doi:10.1029/2003JD003914, 2004.

Yu, H., Kaufman, Y. J., Chin, M., Feingold, G., Remer, L. A., Anderson, T. L., Balkanski, Y., Bellouin, N., Boucher, O., Christopher, S., DeCola, P., Kahn, R., Koch, D., Loeb, N., Reddy, M. S., Schulz, M., Takemura, T., and Zhou, M.: A review of measurement-based assessments of the aerosol direct radiative effect and forcing, Atmos. Chem. Phys., 6, 613-666, doi:10.5194/acp-6-613-2006, 2006.
Zhou, M., Yu, H., Dickinson, R. E., Dubovik, O., and Holben, B. N.: A normalized description of the direct effect of key aerosol types on solar radiation as estimated from aerosol robotic network aerosols and Moderate Resolution Imaging Spectroradiometer albedos, J. Geophys. Res., 110, D19202, doi:10.1029/2005JD005909, 2005.

Zhu, L., Martins, J. V., and Remer, L. A.: Biomass burning aerosol absorption measurements with MODIS using the critical reflectance method, J. Geophys. Res., 116, D07202, doi:10.1029/2010JD015187, 2011. 